\title{
14. The Slow Temporal Relaxation of Meta-Phosphate Glass containing Europium as revealed by Inhomogeneous Linewidth Change in Fluorescence Spectra due to ${ }^{5} \mathrm{D}_{0}{ }^{7} \mathrm{~F}_{0}$. Transition of $\mathrm{Eu}^{3+}$ Ions
}

\author{
By Eisei Takushi, Kazumi Hirata, *) and Takeshi Sasaya*) \\ Department of Physics, College of Science, University \\ of the Ryukyus, Okinawa 903-01
}

(Communicated by Masao Kotani, M. J. A., Feb. 12, 1985)

Recently there has been much interest in the origin of the optical homogeneous and inhomogeneous linewidths of rare-earth ions in amorphous materials and glasses. ${ }^{1)-10)}$ We tried to find phenomena that would indicate that the inhomogeneous linewidths are temporally dependent. In this communication we wish to show that the inhomogeneous linewidth of ${ }^{5} \mathrm{D}_{0}-{ }^{7} \mathrm{~F}_{0}$ fluorescence line of $\mathrm{Eu}^{3+}$ in meta-phosphate glass is a function of time at room temperature.

Measurements of inhomogeneous linewidth were carried out for five samples. Sample compositions were $100 \mathrm{~mol} \% \mathrm{Ca}\left(\mathrm{PO}_{3}\right)_{2}$ with 50, 60, 65, 70 and $82 \mathrm{~mol} \%$ $\mathrm{Eu}^{3+}$. A high pressure mercury lamp (USHIO 500W) was used as the source of excitation. Fluorescence spectra were dispersed with a $50 \mathrm{~cm}$ grating monochromator (1200 lines $/ \mathrm{mm})$. Details of glass preparation and experimental apparatus are given in ref. 11). An energy level diagram and a spectrum profile of the $\mathrm{Eu}^{3+}$ ion $\left({ }^{5} \mathrm{D}_{0}{ }^{-} \mathrm{F}_{0}\right)$ are shown in Fig. 1.

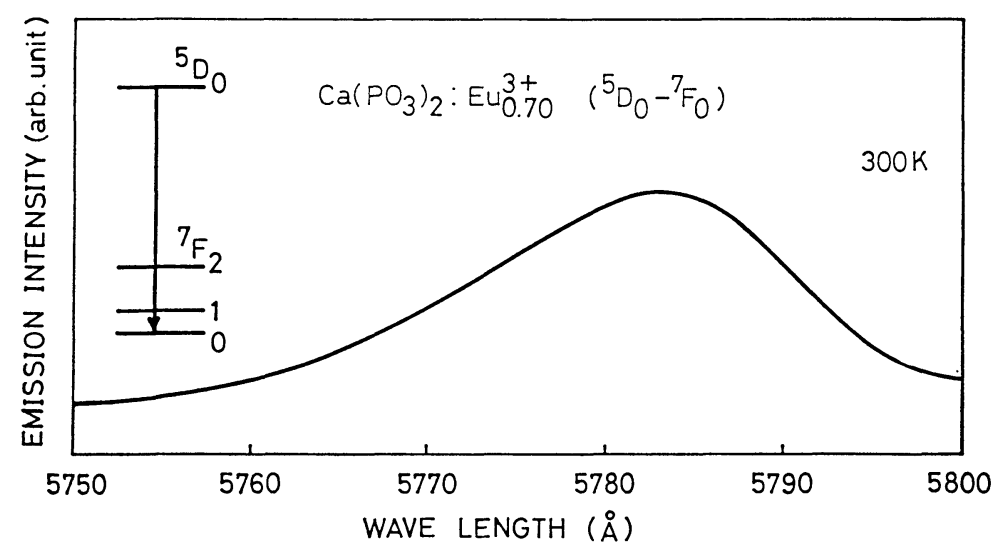

Fig. 1. Spectral shape of the inhomogeneously broadened transition of ${ }^{5} \mathrm{D}_{0}-{ }^{7} \mathrm{~F}_{0}$ emission spectrum of $\mathrm{Eu}^{3+}$ ion $(70 \mathrm{~mol} \%)$ in $\mathrm{Ca}\left(\mathrm{PO}_{3}\right)_{2}$ glass at room temperature.

The temporal shift of the full width at half-maximum (FWHM) of the inhomogeneously broadened ${ }^{5} \mathrm{D}_{0}{ }^{-} \mathrm{F}_{0}$ transition spectra of $\mathrm{Eu}^{3^{+}}$ion in glass are shown in Figs. 2, 3 and 4 plotted against time. The gradual change of FWHM exists in the range from $0.40 \AA$ to $1.85 \AA$ for $50,60,65,70$ and $82 \mathrm{~mol} \% \mathrm{Eu}^{3+}$ ions, respectively.

*) Undergraduate student. 


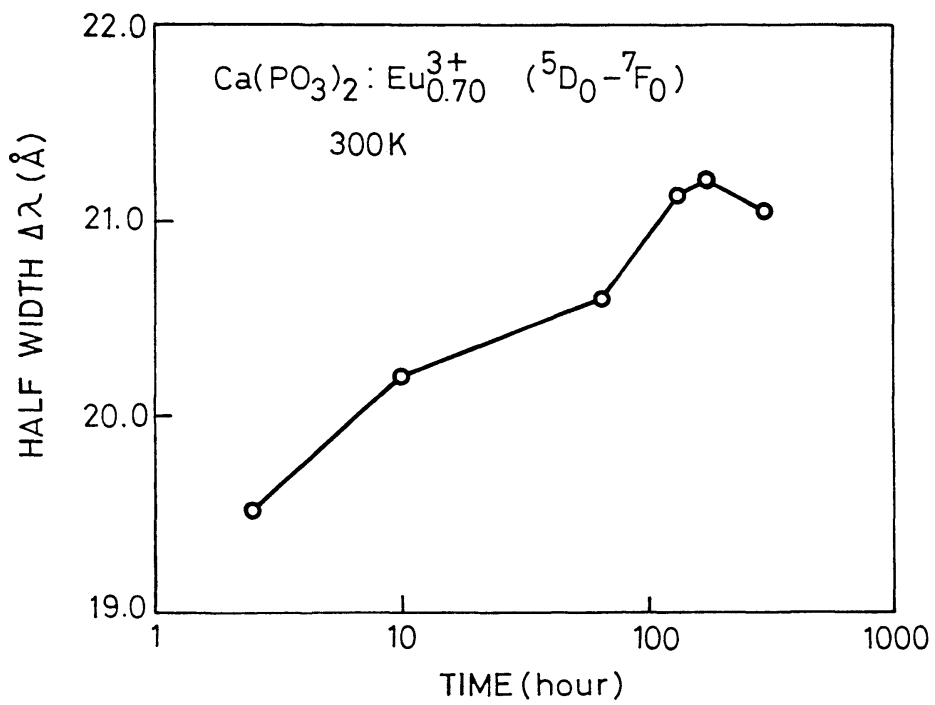

Fig. 2. Time dependence of the half width of ${ }^{5} \mathrm{D}_{0}-{ }^{7} \mathrm{~F}_{0}$ emission spectra of $\mathrm{Ca}\left(\mathrm{PO}_{3}\right)_{2}: \mathrm{Eu}^{3+}(70 \mathrm{~mol} \%)$ at room temperature under the excitation of UV light from a high pressure mercury lamp. The abscissa means the time which has elapsed after the glass sample was taken out of the furnace and cooled to room temperature. A temporal shift of spectral width is observed about $1.85 \AA$ at the time between 2 and $800 \mathrm{~h}$ after glass was formed.

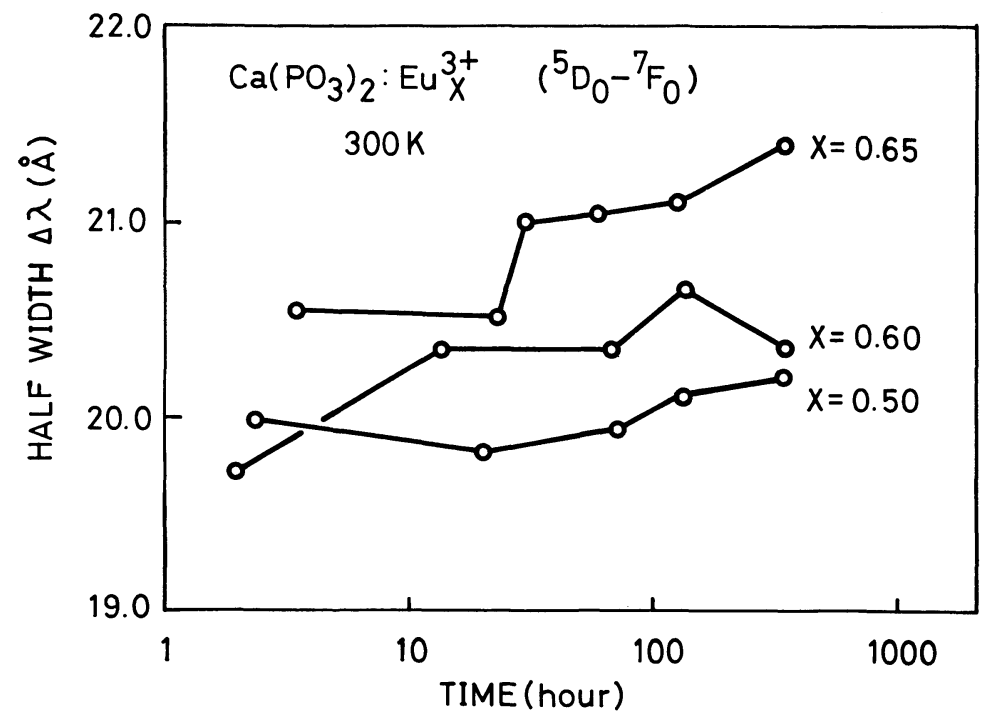

Fig. 3. Time dependence of the half width of ${ }^{5} \mathrm{D}_{0}-{ }^{7} \mathrm{~F}_{0}$ emission spectra of $\mathrm{Ca}\left(\mathrm{PO}_{3}\right)_{2}: \mathrm{Eu}_{X}^{3+}(\mathrm{X}=50,60$ and $65 \mathrm{~mol} \%)$ at room temperature. Temporal shifts of spectral width are observed and show the gradual increase of the spectral width with time. 


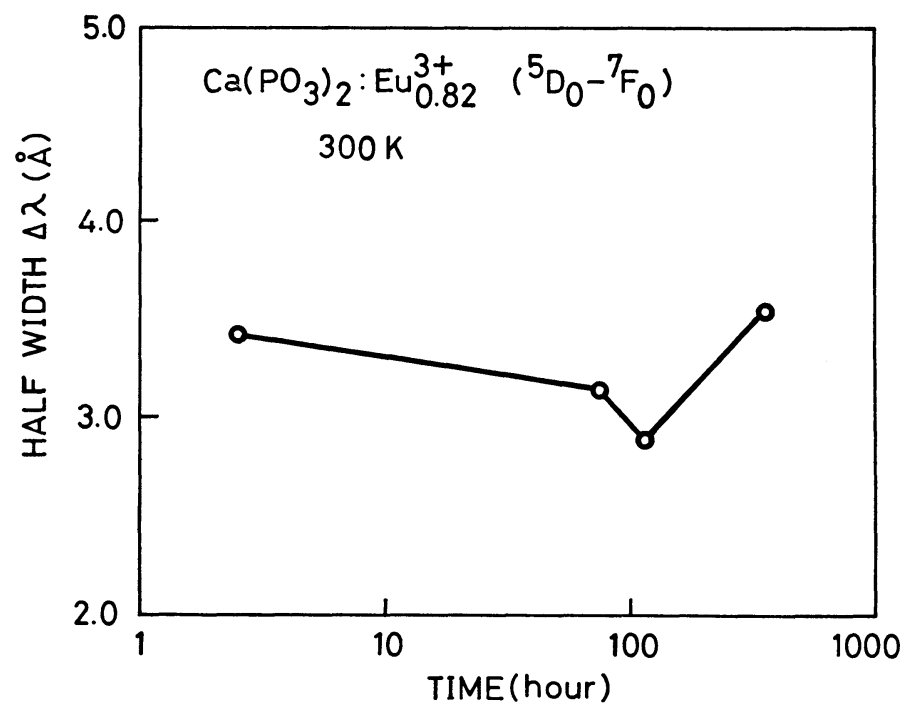

Fig. 4. Time dependence of the half width of ${ }^{5} \mathrm{D}_{0}-{ }^{7} \mathrm{~F}_{0}$ emission spectra of $\mathrm{Ca}\left(\mathrm{PO}_{3}\right)_{2}: \mathrm{Eu}^{3+}(82 \mathrm{~mol} \%)$ at room temperature. Spectral width of about $3.5 \AA$ is very narrow compared with the other concentrations (about 20-21 $\AA$ ). This high concentration doped $\mathrm{Eu}^{3+}$ glass would be in the crystalline state.

In conclusion, judging from the relationship between linewidth increase and time, our results suggest that there exists a variation of the crystal field acting on the $\mathrm{Eu}^{3^{+}}$ions after the glass was formed. We believe that the relaxation, which is a result of the renormalization of the strain in the glass, may be largely responsible for the behavior of these temporal variations in the spectral width.

Finally, an observation of the temporal variation (or shift) of the emission spectra of rare earth ions in glass would give a useful information on the structural changes of glasses and amorphous materials.

The authors would like to thank Mr. Cartis Cairns for comments.

\section{References}

1) M. J. Weber: Laser Spectroscopy of Solids (eds. W. M. Yen and P. M. Selzer). Springer, Berlin (1981).

2) J. R. Morgan et al.: J. Phys. Chem., 85, 747 (1981).

3) N. Motegi and S. Shionoya: J. Luminescence, 81, 1 (1974).

4) T. Kushida and E. Takushi: Phys. Rev., B12, 824 (1975).

5) T. Kushida, E. Takushi, and Y. Oka: Proc. Int. Conf. on Luminescence (Tokyo), p. 146 (1975) ; J. Luminescence, 12/13, 723 (1976).

6) P. M. Selzer et al.: Phys. Rev. Lett., 36, 813 (1976).

7) E. Takushi and T. Kushida: Proc. Int. Conf. on Luminescence (Paris), p. 289 (1978); J. Luminescence, 18/19, 661 (1979).

8) J. Hegarty and W. M. Yen: Phys. Rev. Lett., 43, 1126 (1979).

9) P. Avouris, A. Campion, and M. A. El-Sayed: J. Chem. Phys., 67, 3397 (1977).

10) J. R. Morgan and M. A. El-Sayed: Chem. Phys. Lett., 84, 213 (1981).

11) E. Takushi and K. Hirata: Bull. College of Science, Univ. of the Ryukyus, no. 38, p. 47 (1984). 